\title{
Effects of the thermal environment on human health: an investigation of 30 years of daily mortality data from SW Germany
}

\author{
G. Laschewski* , G. Jendritzky \\ Deutscher Wetterdienst, Business Unit Human Biometeorology, Stefan-Meier-Str. 4, 79104 Freiburg, Germany
}

\begin{abstract}
The objective of this study is to investigate the climate sensitivity of health in a moderate climate of SW Germany. Daily mortality rates for the 30 yr period 1968-1997 for Baden-Württemberg (SW Germany) have been investigated with regard to the possible impacts of the thermal environment. A complete heat budget model of the human being (Klima-Michel model with outcome 'perceived temperature') has been used to assess the atmospheric conditions of heat exchange. Mortality data show a marked seasonal pattern with a minimum in summer and a maximum in winter. During the seasonal minimum in summer, death rates rise sharply with increasing heat load, reaching highest values during pronounced heat waves. Under comfortable conditions, mortality data show the lowest rates. Increasing cold stress also causes death rates to rise. In addition, thermal changes on a time scale of $1 \mathrm{wk}$ have been considered in comparison to short-term exposures. In all seasons changes towards 'warmer' conditions in terms of perceived temperature result in adverse effects, while changes to 'colder' conditions provide relief. This is unexpected for the winter. The daily correlation coefficients between the deviations of perceived temperature and the deviations of mortality rate from the smoothed values (Gaussian filter, $101 \mathrm{~d}$ ) show a pronounced seasonal pattern with significant differences from zero between March and August. From the end of June to the beginning of July, about $25 \%$ of the variance in the deviations of mortality rate from the smoothed values can be explained by the effects of the thermal environment. The winter values show only non-significant correlations, strong day-to-day variability, but marked time lags of $8 \mathrm{~d}$ and more, while in summer there is practically no difference in the results between the zero and $1 \mathrm{~d}$ lags. Cold spells lead to excess mortality to a relatively small degree, which lasts for weeks. The mortality increase during heat waves is more pronounced, but is followed by lower than average values in subsequent weeks.
\end{abstract}

KEY WORDS: Climate impact · Thermal environment $\cdot$ Mortality $\cdot$ Perceived temperature $\cdot$ SW Germany

\section{INTRODUCTION}

In the past most of the epidemiological studies on the impacts of the atmospheric environment on human health dealt with air pollution (Anderson et al. 1996, Katsouyanni et al. 1997, Zmirou et al. 1998, Zeger et al. 1999). Since the discussion on the effects of climate change on human health began, thermal environmental conditions have increasingly been recognised as being of particular importance.

The thermal environment and human beings are closely linked by heat exchange. In order to ensure a constant core temperature of the body, heat production

*E-mail: gudrun.laschewski@dwd.de (metabolic rate) and heat dissipation have to be balanced. An efficient thermal regulation system makes it possible for the bodies of healthy people to react effectively to thermal stress. Thermal comfort can be maintained by thermal regulation and adaptation of behaviour within certain limits of thermal stress and physical activity. Physical and mental work can be carried out without considerable impairment. Additionally thermoregulation and blood pressure control are linked by means of the cardiovascular system. During thermal comfort (neutral) conditions, the demands on the thermal regulatory system are minimal. With increasing thermal stress (heat load or cold stress), the demands on the cardiovascular system increase to enable thermoregulation. After a few days of thermal stress 
a certain 'acclimatisation' will develop, which makes it easier to deal with. Exposure to extreme thermal conditions, however, increases the risk of physiological disturbances considerably. The impairment of the state of health can lead to illness or even death. Especially people with respiratory and cardiovascular diseases, young children and older people, whose capacity to adapt is no longer sufficient, are affected (Eurowinter Group 1997, Guest et al. 1999).

The primary objective of this research is to investigate the climate sensitivity of human health of the population in the moderate climate of SW Germany. The effects of the thermal environment on mortality is explored over the whole year, seasonally, and for summer and winter extreme temperatures. Underlying the analysis is the hypothesis that the relation between thermal conditions and mortality is mainly an expression of maladaptation, which is - besides other factors such as age, health status, etc. - a consequence of (short-term) changes of the prevailing thermal conditions or of the occurrence of thermal extremes. Therefore persistent thermal values will be considered as well as changing thermal values in comparison to short-term exposures.

\section{LITERATURE REVIEW}

The physiologically significant assessment of the complex conditions of heat exchange between the human body and the atmospheric environment requires the application of complete heat budget models (VDI 1998). State-of-the-art procedures combine air temperature, water vapour pressure, wind velocity, short-wave and long-wave radiant fluxes with the metabolic rate in thermo-physiologically significant terms with due consideration given to clothing (VDI 1998).

Frequently used approaches in European applications are the discomfort equation (Fanger 1972), i.e. the basic module in the Klima-Michel model (Jendritzky \& Nübler 1981, Jendritzky et al. 1990) and the Munich energy budget model for individuals (MEMI; Höppe 1993), while in North American applications the (complete/outdoor) apparent temperature (AT) approach (Steadman 1984, 1994) is more common. Blazejczyk (1994) presented the man-environment heat exchange model (MENEX). Possible parameters for a physiologically significant assessment of the thermal environment are the predicted mean vote (PMV; Fanger 1972); PMV*, with Gagge's et al. (1986) improvement in the description of latent heat fluxes; and temperatures related to fixed standard conditions, such as physiologically equivalent temperature (PET; Höppe 1999), perceived temperature (PT; Staiger et al.
1997, Jendritzky et al. 2000a), or AT in different versions (Steadman 1984, 1994). Other representative indices include the standard predictive index of human response approach (Gagge et al. 1986) and Out_SET* (de Dear \& Pickup 2000, Pickup \& de Dear 2000), which is based on Gagge's work, and the extensive work by Horikoshi et al. $(1995,1997)$ which resulted in a thermal environmental index.

For reasons of data availability, the majority of the studies on the climate sensitivity of human health is concerned with mortality data. However, mortality data reflect only extremes, the tip of the iceberg. It seems highly possible that the thermal environment also impacts morbidity, the well-being and efficiency of the human organism.

Seasonal variations in mortality have been found for many causes of death, especially cardiovascular and respiratory diseases. It is assumed that some of these seasonal variations in mortality can be ascribed to the effects of outdoor air temperature (Kunst et al. 1993, Saez et al. 1995, Laake \& Sverre 1996, Eng \& Mercer 1998, Lerchl 1998, Pell \& Cobbe 1999). The relation of mortality data to thermal conditions shows a typical seasonal pattern with a maximum in February and a minimum in August (Sakamoto-Momiyama 1977). In general the seasonal trend is more pronounced in temperate climates than in extreme climates (SakamotoMomiyama 1977). Statistical studies on the influence of thermal conditions on the daily mortality data in different countries showed a minimum of mortality under certain thermal conditions (referred to as the comfort range), whereby thermal conditions were mostly described by air temperature. Several studies were able to show that the prevalent climate of a geographic area determines the optimal thermal range for minimum mortality (Kunst et al. 1993, Pan et al. 1995, Ballester 1997, Alberdi 1998, Rooney et al. 1998). An increase in mortality is recorded outside the comfort zone (Jendritzky et al. 2000a). It can be caused either by very hot summers or very cold winters (Larsen 1990, Kalkstein 1993). The mortality rate rises evidently with increasing cold stress (Eurowinter Group 1997). A study of mortality data from Canada, however, shows that the mortality rate declines under extremely cold conditions (Frost \& Auliciems 1993). This is probably due to people from risk groups avoiding exposition (behavioural adaptation). Mortality also rises with increasing heat load. Studies in the USA, Canada, Greece, and China show that significantly more than the expected deaths occur after a certain threshold for thermal stress is exceeded, which obviously depends on climate (Kalkstein \& Smoyer 1993, Katsouyanni et al. 1993).

The increase in mortality during extreme heat is partly compensated for by lower mortality in the sub- 
sequent weeks (Kunst et al. 1993, Rooney et al. 1998). This suggests that people die who would have died in the short term anyway ('mortality displacement'; Alberdi 1998). On the other hand, a proportion of the additional mortality during extreme heat also concerns avoidable deaths and is consequently combined with a considerably diminished longevity (Eng \& Mercer 1998).

Mortality rates and thermal stress seem to be more closely linked in summer than in winter (Kalkstein \& Greene 1997), because in summer there is often more direct exposure to outdoor conditions than in winter. Moreover, other effects, such as a higher risk of infection, partly reflect the relation in winter. In addition to direct exposure to thermal extremes, other factors, such as demographic composition, urban morphology, access to air conditioning and socioeconomic conditions, play a role in the vulnerability of the population (Kalkstein \& Greene 1997, Davis et al. 1999, Smoyer et al. 2000).

With climate change, heat waves are expected to be more frequent and/or more severe (McGeehin \& Mirabelli 2001). This could mean a significant increase in the mortality rate in the summer months. Regions with only irregularly recurring extremes would be especially affected (Kalkstein 1993). Hence, Germany with its moderate climate characterised by rare extremes also counts as a risk region.

\section{MATERIALS AND METHODS}

3.1. Mortality data. A time series of $30 \mathrm{yr}$ of daily mortality data (total mortality, MR) for the period 1968-1997 (approx. 2.8 million cases) from BadenWürttemberg (SW Germany, about 10.5 million inhabitants) was investigated with regard to possible impacts of the thermal environmental conditions. Annual population data were obtained from the Baden-Württemberg State Statistics Office. In order to obtain daily population estimates, the annual data which are valid for 31 December each year were interpolated linearly. The daily mortality data were then standardised to 100000 inhabitants to take the fluctuating size of the population in this period into account. (The number of inhabitants has increased from 8.5 million in 1968 to 10.5 million in 1997.) The mortality data reflect pronounced influenza effects in January, February and March 1968, in February and March 1978 and in February and March 1986. The most dramatic influenza epidemic occurred in January 1970, when the total mortality rate increased up to more than double the usual numbers. The effects of influenza have been removed statistically from the time series. (For that a low-pass filter was applied to the time series.
Then all data during the time of the influenza epidemics were excluded and the gaps filled by means of linear interpolation. Finally the high frequencies of the original time series were added to the interpolated data.) A discrimination of mortality data according to age groups and gender was not yet available. The age groups most at risk have changed in their proportion of the general population. The young $(<4$ yr $)$ have decreased by about $8 \%$ and the elderly ( $>65$ yr) have increased by about $4 \%$. Due to the general population increase in Baden-Württemberg, in total there were more people at high risk in 1997 as compared to 1968 (although their proportion in the population had decreased).

3.2. Meteorological data. As opposed to the approaches used in many other studies, where air temperature alone was taken in order to cover the thermal conditions, a complete state-of-the-art heat budget model of the human being (Klima-Michel model) has been applied (Jendritzky \& Kalkstein 1997), because temperature is not the only relevant variable for the thermo-physiologically significant assessment of the atmospheric environment. The parameter used here is the so-called perceived temperature (PT), which takes relevant mechanisms of heat exchange into account with due consideration given to well-adapted clothing. Hence air temperature, water vapour pressure, wind velocity and short-wave and long-wave radiant fluxes are the meteorological input variables.

$\mathrm{PT}$ is the air temperature $\left({ }^{\circ} \mathrm{C}\right)$ of a reference environment in which the perception of heat and/or cold is the same as under the actual conditions. In the reference environment the wind velocity is reduced to a light draught and mean radiant temperature is equal to air temperature (such as inside a dense forest). The water vapour pressure is identical with that of the actual environment as long as it is not reduced by condensation. Perceived heat and cold is computed by means of the comfort equation (Fanger 1972) using the PMV* correction of Gagge et al. (1986) in order to consider the latent heat fluxes more realistically. The thermophysiological assessment is made for a male person, the 'Klima Michel', aged 35 yr, $1.75 \mathrm{~m}$ in height and weighing $75 \mathrm{~kg}$. His work performance is $172.5 \mathrm{~W}$, which corresponds to walking at approximately $4 \mathrm{~km} \mathrm{~h}^{-1}$ on flat ground. The assessment procedure is designed for outdoors. Accordingly, the standard male will choose between summer and winter clothes, in order to gain as much thermal comfort as possible. Summer clothes ( 0.5 clo) correspond to a pair of light long trousers, a short-sleeved shirt and sandals; winter clothes (1.75 clo), in this approach, correspond to a suit of woollen material, a tie, a winter coat and warm, solid shoes.

The State of Baden-Württemberg covers an orographically structured area of about $35000 \mathrm{~km}^{2}$ (about 
$220 \mathrm{~km}$ from north to south and $160 \mathrm{~km}$ from east to west). In order to achieve a representative data set related to the area of interest, daily mean values of PT from 4 weather stations (Freiburg, Karlsruhe, Stuttgart and Konstanz) are averaged to represent the area mean. The weather stations are located in urban areas or their outskirts in the southwestern, northwestern, northeastern and southeastern part of the state. The data describe the meteorological conditions where the majority of the population lives rather than representing the 'mean' conditions of the whole region. The daily mean value of the perceived temperature for each station has been calculated on the basis of 6-hourly meteorological measurements.

3.3. Data processing. Several methods of data processing were used (such as smoothing, lagging, division into classes, creating a parameter to describe changing thermal stress, separation of extreme events, etc.) in order to investigate different aspects of the effects of the thermal environment on mortality. The approaches and the rationales for these methods are described below.

3.3.1. Smoothing: The data of PT and MR were smoothed to obtain estimates of the baselines or 'normal' conditions. Daily PT and MR were then overlaid for comparison. The smoothed data sets of PT and MR were calculated on the basis of a Gaussian smoothing, with a filter response function $R$ :

$$
R(f)=\exp \left(-1 / 3 \Pi^{2} f^{3}\right)
$$

where $f=$ the frequencies of the time series.

In order to be able to decide on the appropriate filter length, different periods from 3 to $121 \mathrm{~d}$ were tried out. Finally the $101 \mathrm{~d}$ filter was chosen because it turned out to be the shortest possible filter that provided a sufficiently smooth pattern of the data. Obviously this decision depends on the pattern of the time series; no objective criterion was applied.

3.3.2. Lagging: Unless otherwise indicated, the daily MR were related to the mean PT on each previous day throughout the whole analysis. Usually this is referred to as a $1 \mathrm{~d}$ lag. The rationale for using this lag is that our data do not contain information about the time of death. The deaths that occurred during the first half of the day could not be influenced by the meteorological conditions later in the afternoon. As daily mean values of PT were used, the data of the previous day were assumed to better describe the possible environmental influences on mortality. Other lags (up to $14 \mathrm{~d}$ ) were also used for the calculation of correlations and autocorrelations of PT and MR.

3.3.3. Parameter for describing changing thermal stress: In order to take into account the effects of changing thermal stress on mortality, the parameter PT7 was introduced. PT7 (in K) describes the deviation of the previous day's PT from the linearly weighted mean of PT of the preceding $7 \mathrm{~d}$ (i.e. the weights decrease from $7 / 28$ for PT[day-2] to $1 / 28$ for PT[day-8]). Due to the lack of physiologically based data, the relevant time scale of human adaptation to the prevailing thermal conditions was a priori chosen to be $1 \mathrm{wk}$. By representing short-term changes in comparison to the prevailing thermal conditions, PT7 is intended to describe the demands on adaptation.

3.3.4. Division into classes: The MR data were divided into classes of PT. This method was used to partly summarise the data with the further intention of gaining better insight into the data structure. The classes of PT have a range of $4^{\circ} \mathrm{C}$, above and below $0^{\circ} \mathrm{C}$, i.e. towards higher and lower temperatures. Altogether 11 classes were used, covering the thermal range from -16 to $28^{\circ} \mathrm{C}$. (Examples: the deaths that occurred on all days with daily mean values of perceived temperature of $8^{\circ} \mathrm{C} \leq \mathrm{PT}<12^{\circ} \mathrm{C}$ or $-4^{\circ} \mathrm{C} \leq$ $\mathrm{PT}<0^{\circ} \mathrm{C}$ were grouped together.) The class range was selected a priori; other classes are possible, but were not used. A minimum of 100 cases (i.e. days) per class is required for statistical reasons (needed to estimate the confidence intervals when assuming normal distribution is not reasonable). At the fringes the classes do not meet this condition, hence they are open (containing all cases above/below the highest/ lowest class).

Further, the MR data were divided into classes of PT7. The classes of PT7 cover a range of $4 \mathrm{~K}$, but, as opposed to classes of PT, they are centred around $0 \mathrm{~K}$ (examples: $-6 \mathrm{~K} \leq \mathrm{PT} 7<-2 \mathrm{~K}$ or $-2 \mathrm{~K} \leq \mathrm{PT} 7 \leq 2 \mathrm{~K}$ or $6 \mathrm{~K}<\mathrm{PT} 7 \leq 10 \mathrm{~K})$. This was done to separate almost indifferent thermal conditions from a distinct warming or cooling.

3.3.5. Definition of seasons: Two definitions of seasons were used. Whenever the results refer to certain months, a formal definition of seasons (spring: March, April, May; summer: June, July, August; autumn: September, October, November; winter: December, January, February) was applied. Additionally - wherever the results refer to summer and winter without indicating certain months - the following definitions were used: The beginning of summer was defined as when PT first rises above $20^{\circ} \mathrm{C}$, and the end occurs when PT rises above this threshold for the last time. This approach leads to a variable duration of summer, but is assumed to be better adapted to the problem of 'thermal environment' than the schematic definition of summer as June, July and August. Analogously, the schematic definition of winter as December, January and February was replaced by a threshold of $\mathrm{PT}_{\text {; }}$ the winter begins when PT first falls below $5^{\circ} \mathrm{C}$ and ends when PT falls below $5^{\circ} \mathrm{C}$ for the last time. In the $30 \mathrm{yr}$ average these definitions lead to a mean duration of 
$93 \mathrm{~d}$ for summer and $85 \mathrm{~d}$ for winter, which is comparable to the formal definitions.

3.3.6. Calculation of correlations and autocorrelations: The rationale for calculating correlations between MR and PT is based on the hypothesis that MR is more closely related to the thermal environment if the human organism is not adapted to the actual thermal conditions. Under this assumption one should expect that deviations of PT from the 'normal' conditions (deviations dPT from the filter curve) coincide with an increase in MR above the 'normal' level (deviations $\mathrm{dMR}$ from the filter curve). To support this hypothesis, the correlation coefficient between the value of $\mathrm{dPT}$ and the value of dMR was calculated for each day. Hence the daily correlation coefficient for each July day uses the 30 values from each of the years in the study. Obviously this method presupposes a long time series.

Further, an autocorrelation analysis was made (i.e. the time series of MR and PT, respectively, were correlated with themselves, taking into account different time lags) in order to examine the data independence and possible cyclic variations of the data.

3.3.7. Extreme events: In order to be able to look at extreme events the smoothed time series of PT and MR were used. It has been assumed that the continuously smoothed data describe the 'normal' pattern of the PT time series during the special course of each year better than a fixed assumption of PT values (such as daily averages over the 30 years) and related absolute thresholds. This procedure would take into account the special thermal pattern of each year, such as a mild winter, a warm spring or a cool summer. The method is based on the idea that the population gradually adapts to the changing thermal conditions during the course of the year. The relation between thermal conditions and mortality is assumed to be an expression of maladaptation, which is (beside other factors) a consequence of short-term changes compared to the prevailing thermal conditions. That is why heat waves and cold spells were defined in a relative rather than an absolute way on the basis of the parameter dPT (deviation of PT from the smoothed data that are assumed to describe 'normal' or prevailing conditions). As there is no common definition of an extreme event, different thresholds of dPT (in steps of $1^{\circ} \mathrm{C}$ ) were tried. The results of 3 different thresholds of dPT were compared separately. These thresholds were chosen to meet the following assumptions as closely as possible: (1) only 1 heat wave/cold spell occurred in 30 years, (2) on average 1 heat wave/cold spell occurred every 2 years and (3) on average 1 heat wave/cold spell occurred each year. The different thresholds have provided the possibility of learning about the influence of the intensity of extreme events (measured by dPT) on mortality. Extreme events have been expected to have a minimum duration of $2 \mathrm{~d}$, in order to be able to differentiate between 1 hot day/cold day and a heat wave/cold spell.

\section{RESULTS}

\subsection{Annual variation in thermal response}

The time series of MR and daily mean PT in SW Germany show a marked seasonal pattern (Figs. 1 \& 2): minimum MR in August and maximum MR in February; maximum PT in July and minimum PT in January. Apart from the day-to-day fluctuations, MR and PT surprisingly show variations lasting from some days to weeks, even in the plots of the mean values (30 yr average). This variability is especially pronounced in summer and winter.

The autocorrelation coefficients of MR and PT were calculated for summer and winter separately. PT shows a higher autocorrelation than MR. The autocorrelation of $\mathrm{PT}$ is higher in winter than in summer, with $\mathrm{r}=0.5$ at a lag of $4 \mathrm{~d}$ in summer and at a lag of $6 \mathrm{~d}$ in winter. MR is less closely correlated, with $\mathrm{r}=0.5$ at a lag of $2 \mathrm{~d}$ in summer and a lag of $1 \mathrm{~d}$ in winter (Fig. 3). Hence, mortality data can be assumed to be nearly independent from each other, while PT shows a persistence of a few days.

Considering the deviations of the smoothed data of MR and PT from the $30 \mathrm{yr}$ average (Fig. 4), PT shows a symmetrical pattern in relation to its extreme values, while the pattern of MR is asymmetrical. This is made obvious by an inflection point in mid-May. Afterwards the slope of the MR plots in spring/early summer (May, June and July) is less steep than in autumn. A time lag of $21 \mathrm{~d}$ between the maximum PT and the minimum MR, was found. Almost the same lag is also true for winter.

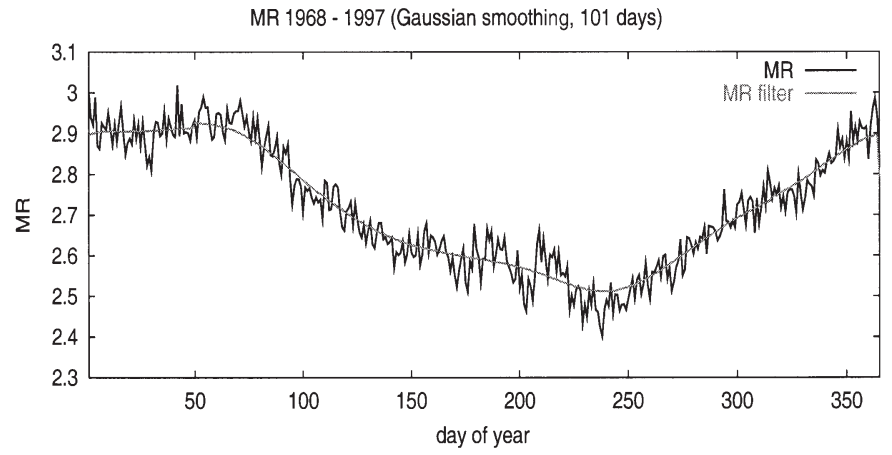

Fig. 1. Mean total mortality rate (MR; per 100000 inhabitants) in SW Germany for 1968-1997 and smoothed values of mean MR 


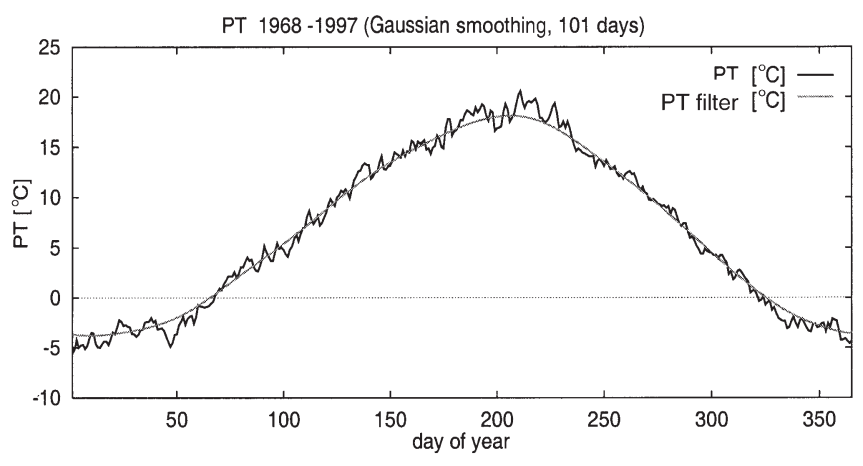

Fig. 2. Mean values of daily mean perceived temperature (PT) in SW Germany for 1968-1997 and smoothed values of mean PT

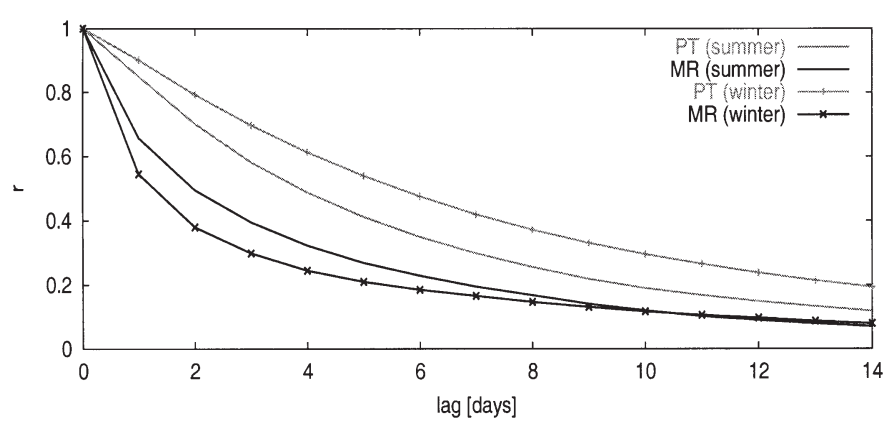

Fig. 3. Autocorrelation coefficients of PT and MR in summer and winter with different lags

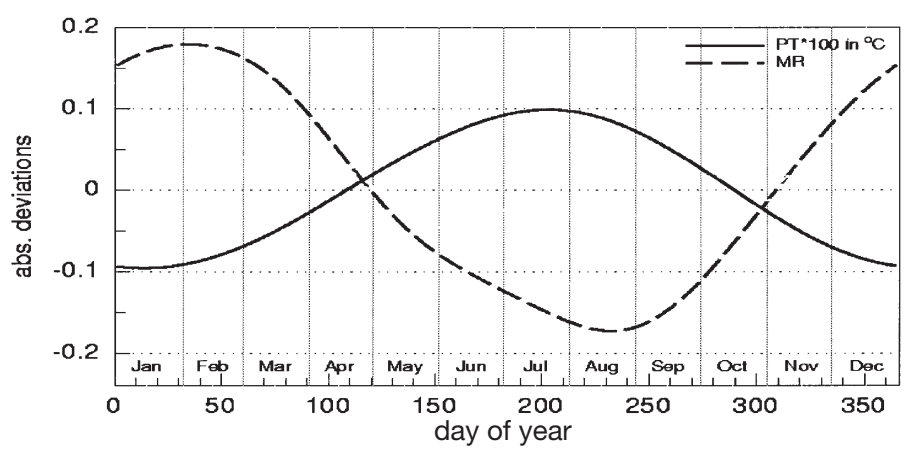

Fig. 4. Deviation of the mean values of PT and MR from the mean of 1968-1997

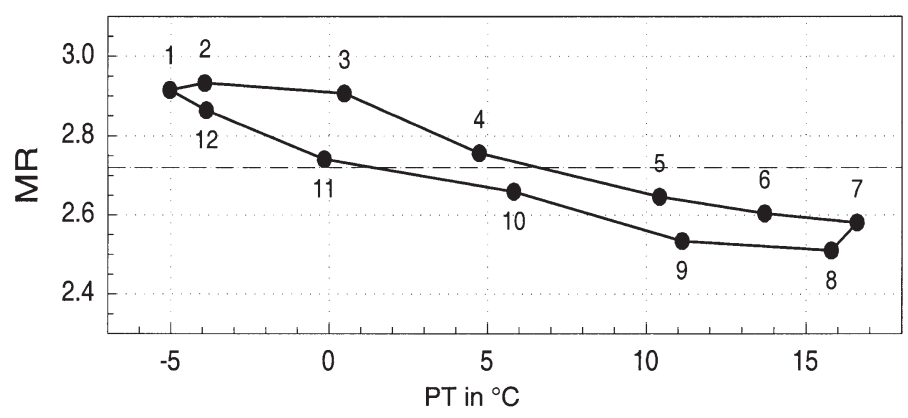

Fig. 5. Monthly mean values (1968-1997) of PT and MR

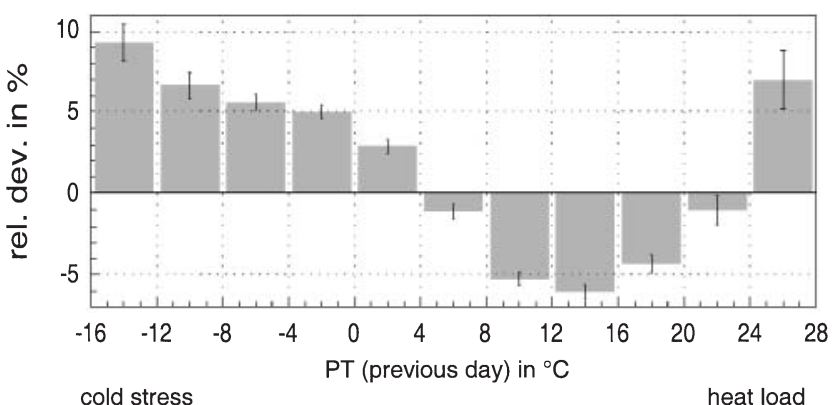

Fig. 6. Mean relative deviation of MR for classes of mean PT of the previous day (class width: $4 \mathrm{~K}_{i}$ range bars: confidence interval at the 0.05 significance level)

In accordance with the asymmetrical pattern of MR (Fig. 4), the seasonal variation (monthly mean values of $\mathrm{PT}$ and MR) possesses a hysteresis (Fig. 5). MR during the seasonal change from winter to summer is about $5 \%$ higher than in the second half of the year, although the monthly mean thermal conditions are the same.

Daily MR was related to classes of daily mean PT on each previous day. The mean relative deviations of MR from the $30 \mathrm{yr}$ average (dMR) of different time scales were taken into consideration (Fig. 6: whole period; Fig. 7: seasons). The relationship for the whole period results in a skewed Vshaped distribution with a minimum in the PT class between 12 and $16^{\circ} \mathrm{C}$, a continuous rise with increasing cold stress and a more marked increase on the heat load side (Fig. 6). The mortality increase due to heat load during the seasonal mortality minimum is particularly remarkable.

The seasonal relations (Fig. 7) indicate that the PT classes with corresponding minimal MRs change with the season. In spring, summer and autumn, PT values between 8 and $16^{\circ} \mathrm{C}$ are associated with the lowest dMR values, while in winter this is valid for the classes between -12 and $+4^{\circ} \mathrm{C}$, which do not differ significantly. Slightly cool conditions (PT class between 4 and $8^{\circ} \mathrm{C}$ ) already lead to an increase in MR in summer. Hot conditions in summer are associated with a very pronounced mean increase in MR of $13 \%$ above the seasonal mean value. In the other seasons mainly increasing negative values of PT lead to increases in MR.

Considering the smoothed data (Gaussian filter, $101 \mathrm{~d})$, the correlation coefficients between dPT of the previous day and dMR from the smoothed values show a pronounced seasonal pattern (Fig. 8). With strong day-to-day fluctuations the coefficients are significantly different from zero 


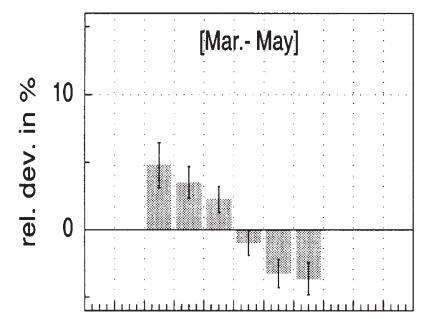

$-16-12-8 \quad-4 \quad 0 \quad 4 \quad 8 \quad 1216202428$
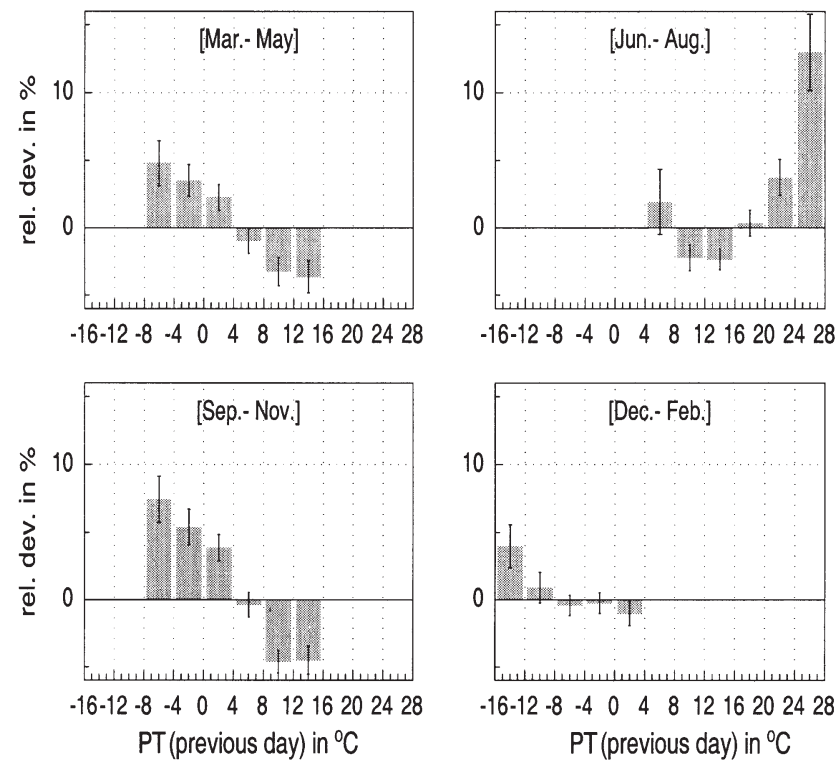

Fig. 7. Mean relative deviation of MR from seasonal mean value of MR for classes of daily mean PT of the previous day (class range: $4 \mathrm{~K}_{i}$ range bars: confidence interval at the 0.05 significance level)

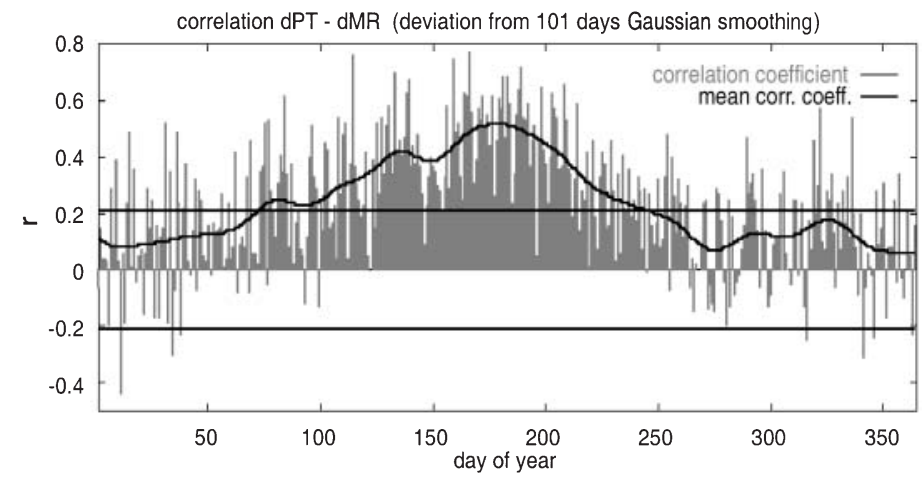

Fig. 8. Correlation coefficients of the deviation of daily mean perceived temperature (dPT) of the previous day and the deviation of mortality rate (dMR) from the smoothed values (correlation coefficients $r \leq 10.211 \mid$ are not significant at the 0.05 significance level)

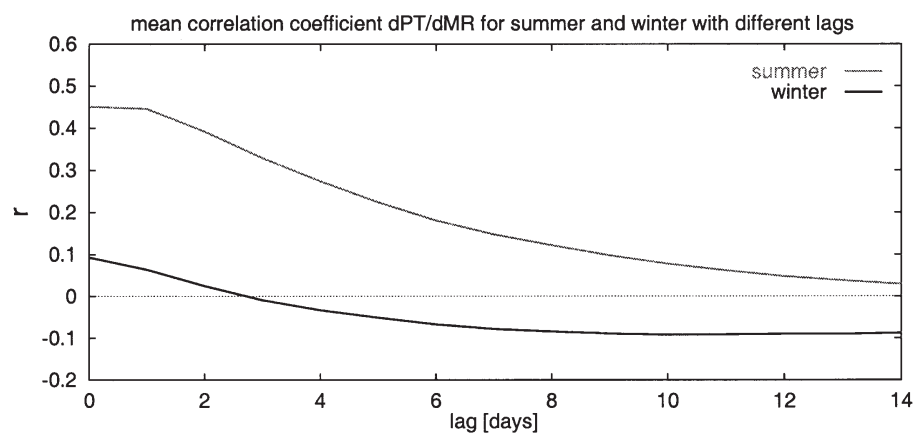

Fig. 9. Mean correlation coefficients of dPT of the previous day and dMR from the smoothed values for summer and winter with different lags between March and August, with mean maximum values greater than 0.5 from the end of June to the beginning of July. In the $30 \mathrm{yr}$ average 19 cases of values greater than $r=0.6$ and 5 cases of values greater than $r=0.7$ were found, mainly in June and July. With the lowest values in September, the mean correlation coefficient increases again in October and November, but remains non-significant. The winter values show strong day-to-day variability as well, but only nonsignificant mean correlations.

The mean correlation coefficients between dPT and dMR (Fig. 9) show marked time lags of $8 \mathrm{~d}$ and more in winter, while in summer zero lag and a $1 \mathrm{~d}$ lag provide practically the same results.

\subsection{Adaptation to changing thermal stress}

Fig. 10 shows the assignment of the mean relative deviation of MR from the $30 \mathrm{yr}$ average to classes of PT7, which describes the deviation of the previous day's PT value from the weighted mean of the 7 preceding PT values in order to achieve a parameter to define (to a certain degree) the demands on adaptation. Increasing positive values of PT7 result in an increase in MR, i.e. changes to warmer conditions result in adverse effects. Increasing negative values of PT7 result in a decrease in $M R$, i.e. changes to colder conditions provide relief.

Looking at dMR in relation to PT7 (Fig. 11), the results show a pattern comparable to Fig. 10. The findings of Fig. 10 are obviously valid for all seasons (Fig. 11), hence leading to a contradiction in winter. As is shown in Figs. 6 \& 7, increasing cold stress corresponds to an increasing $M R$, and apparently (Figs. 10 \& 11) changes to colder conditions provide relief. In order to find a way out of this contradiction, MR were assigned to both PT classes and PT7 classes (Table 1).

According to Table 1 in a $\mathrm{PT}$ range between 12 and $16^{\circ} \mathrm{C}$ mortality is minimal. Increasing values of PT7 mean increasing values of MR in almost all cases. If $\mathrm{PT}$ is up to $8 \mathrm{~K}$ lower or higher than the optimum (i.e. PT range between 4 and $24^{\circ} \mathrm{C}$ ) it depends on PT7 whether MR is higher or lower than the average value. Changes to warmer conditions mean an increase in $M R$, changes to colder conditions mean a decrease in $\mathrm{MR}$. If PT is lower than $4^{\circ} \mathrm{C}$ or higher than $24^{\circ} \mathrm{C}$, $\mathrm{MR}$ is almost always higher than the average values. Consequently temperature changes are especially important for moderate values of $\mathrm{PT}$, i.e. in the transitional seasons. Extreme values of PT are always associated with an increase in MR. 


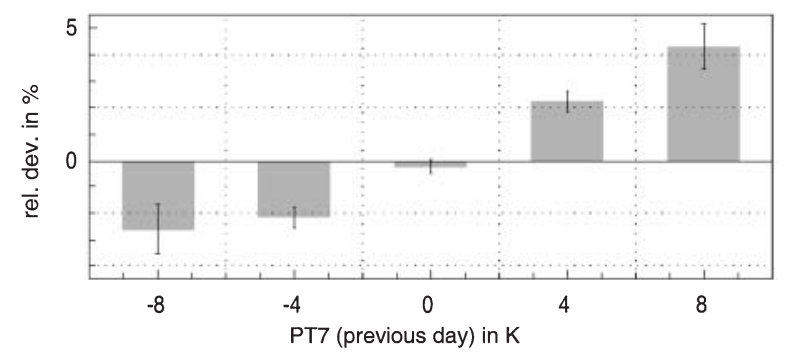

Fig. 10. Mean relative deviation of MR for classes of the deviation of mean PT of the previous day from the preceding 7 days (PT7) (class range: $4 \mathrm{~K}$; range bars: confidence interval at the 0.05 significance level)
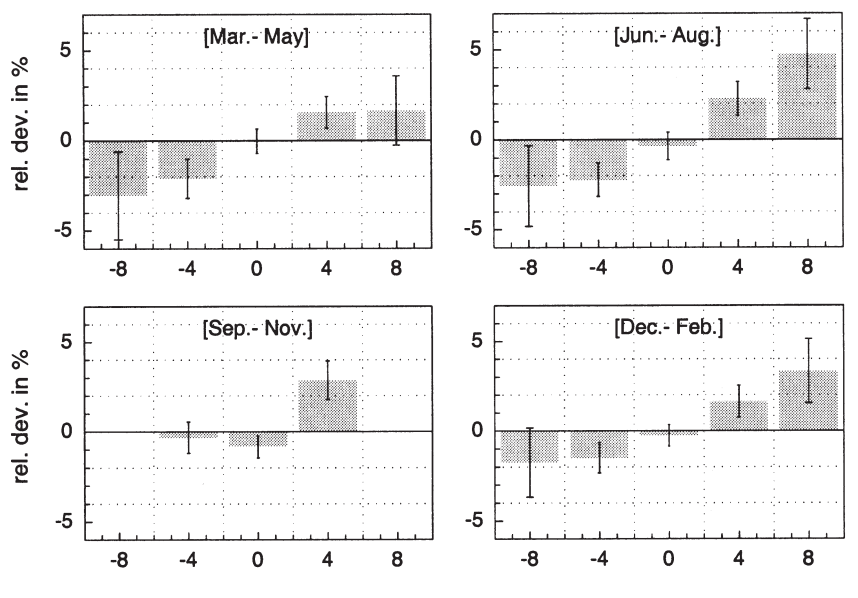

PT7 (previous day) in $\mathrm{K}$

PT7 (previous day) in $\mathrm{K}$

Fig. 11. Mean relative dMR for PT7 classes (class width: $4 \mathrm{~K}$; range bars: confidence interval at the 0.05 significance level)

\subsection{Heat waves}

Heat waves were defined on the basis of dPT. During the 30 summers of observation, a threshold of $\mathrm{dPT}=$ $+12^{\circ} \mathrm{C}$ is exceeded only once, $\mathrm{dPT}=+9^{\circ} \mathrm{C} 16$ times and $\mathrm{dPT}=+8^{\circ} \mathrm{C} 51$ times. Between 1968 and 1997 the most severe heat wave occurred on 30 June 1987 (Fig. 12a). PT rose $12.4^{\circ} \mathrm{C}$ above the 'expected' value. The PT rise of a total of $16^{\circ} \mathrm{C}$ began $4 \mathrm{~d}$ before the day with the largest dPT value. Above-'normal' values of PT were observed over a period of $10 \mathrm{~d}$. With a time lag of $1 \mathrm{~d}$ in relation to the hottest day, an increase in MR of $24.6 \%$ was observed, embedded in $3 \mathrm{~d}$ with positive values of dMR centred around the hottest day. No pronounced trend in MR associated with that heat wave was observed: dMR fluctuated between positive and negative values, resulting in a mean net value of $+2.7 \%$ during the 2 weeks after the hottest day, i.e. a small net increase in the mortality rate.

The average of the 15 most severe heat waves (except the 1987 heat wave) are characterised by a PT increase of $9.8^{\circ} \mathrm{C}$ above the 'expected' value and a total period of $10 \mathrm{~d}$ with above-'normal' values of PT (Fig. 12b). This was accompanied by $9 \mathrm{~d}$ with positive $\mathrm{MR}$ values, i.e. a mean value of $\mathrm{dMR}=+4.3 \%$. The highest dMR values $(+12.1 \%)$ were observed $1 \mathrm{~d}$ after the hottest day. Three $d$ after the hottest day a period of $3 \mathrm{wk}$ began with a less than normal MR, i.e. a mean value of $\mathrm{dMR}=-2.5 \%$.

An evaluation of an additional 35 heat waves (excluding the 16 most severe heat waves) leads to similar

Table 1. Mean daily deviation of MR (in \%) from the $30 \mathrm{yr}$ average (numbers in the middle of each square) dependent on mean daily PT and on PT7 (class range: $4 \mathrm{~K}$; small numbers at the top: number of data in class; small numbers at the bottom: confidence interval in \%). Light shading: MR below average; dark shading: MR above average; no shading: with consideration of the confidence interval MR indifferent to average

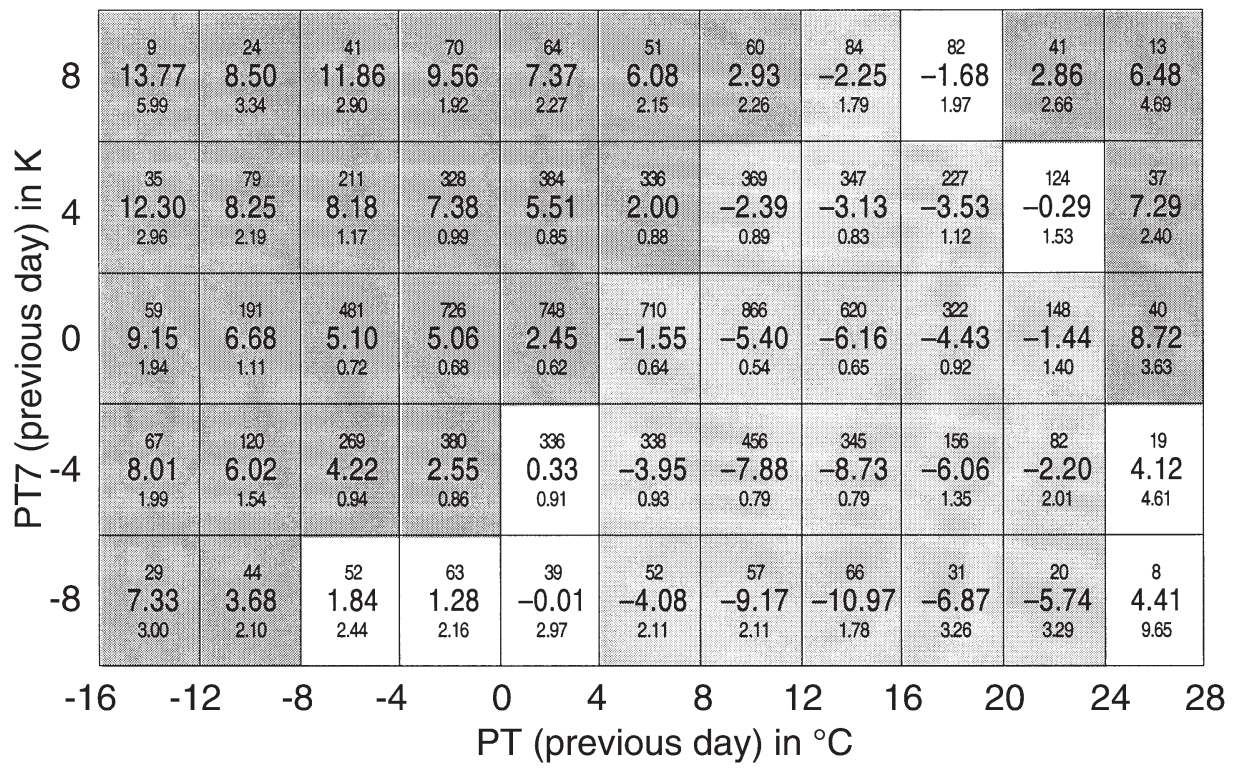


a) heat wave 1987
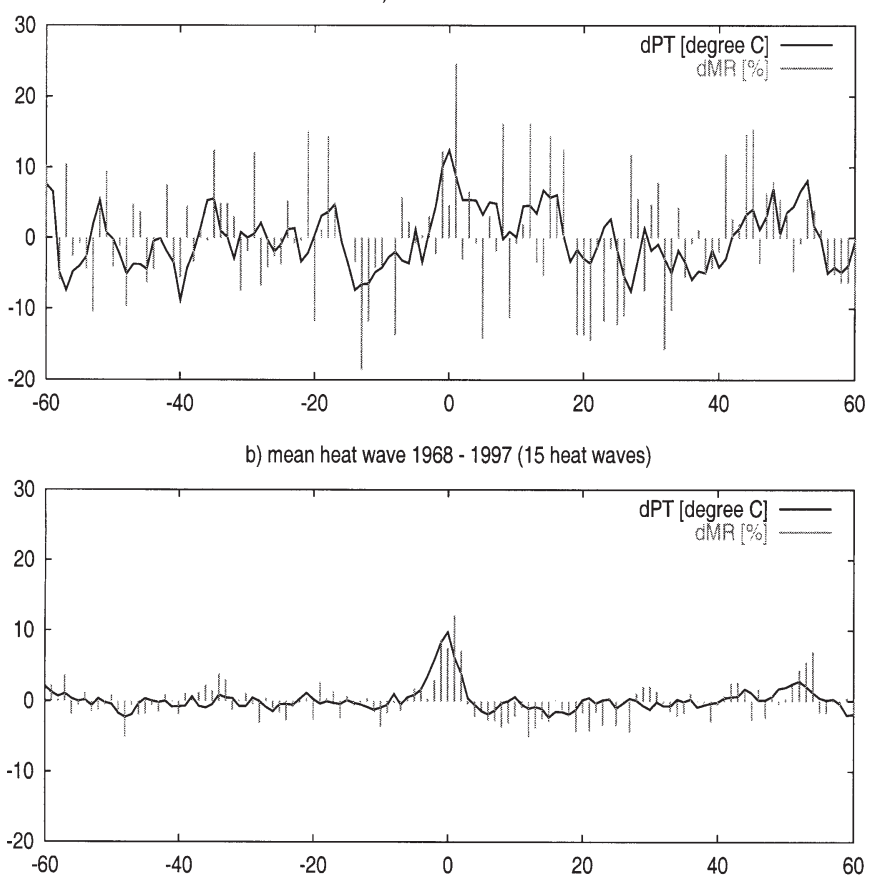

c) mean heat wave $1968-1997$ ( 35 heat waves)

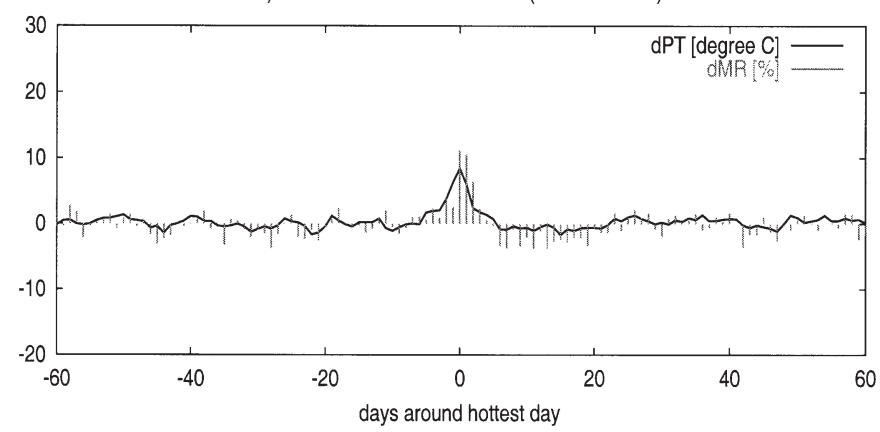

Fig. 12. Mean dPT and dMR from the smoothed time series of PT and MR for (a) the most severe heat wave, (b) the 15 most severe heat waves (except the 1987 heat wave), and (c) 35 heat waves (16 most severe heat waves excluded) between 1968 and 1997

results (Fig. 12c). A total period of $11 \mathrm{~d}$ with higher than normal PTs occurred in the mean of these 35 heat waves. The hottest day is characterised by a dPT value of $+8.5^{\circ} \mathrm{C}$ and a dMR value of $+11.2 \%$ (with a time lag of $1 \mathrm{~d} \mathrm{dMR}=+10.8 \%$ ). Twelve days with a higher than normal MR (having a mean value of $\mathrm{dMR}=+3.8 \%$ ) were observed, followed by $18 \mathrm{~d}$ with less than normal $\mathrm{MR}$ (having a mean value of $\mathrm{dMR}=-2.3 \%$ ) which began $5 \mathrm{~d}$ after the hottest day.

The mean characteristics of 51 heat episodes in SW Germany from 1968 to 1997 are: duration of abovenormal PT values: $11 \mathrm{~d}$; hottest day: $\mathrm{dPT}=+9.0^{\circ} \mathrm{C}$; duration of above-normal MR values: $10 \mathrm{~d}$ with mean increase in mortality $\mathrm{dMR}=+3.9 \%$; and duration of subsequent below-normal MR values: $19 \mathrm{~d}$ with a mean decrease in mortality $\mathrm{dMR}=-2.3 \%$.

\subsection{Cold spells}

Cold spells were defined on the basis of dPT. During the 30 winters of observation a threshold of $\mathrm{dPT}=$ $-16^{\circ} \mathrm{C}$ was exceeded only once, a threshold of $\mathrm{dPT}=$ $-12^{\circ} \mathrm{C} 13$ times and $\mathrm{dPT}=-9^{\circ} \mathrm{C} 44$ times.

Between 1968 and 1997 the most severe cold spell occurred on 12 January 1987 (Fig. 13a). PT dropped $16.6^{\circ} \mathrm{C}$ below the 'expected' value. The PT decrease began $2 \mathrm{~d}$ before the coldest day. Below-'normal' PT values were observed over a total period of $9 \mathrm{~d}$. No pronounced trend in the MR was observed to be associated with that cold spell: dMR fluctuated between positive and negative values, resulting in a mean net value of $+1.7 \%$ during the 2 wk after the coldest day, i.e. a small but non-systematic increase in the mortality rate.
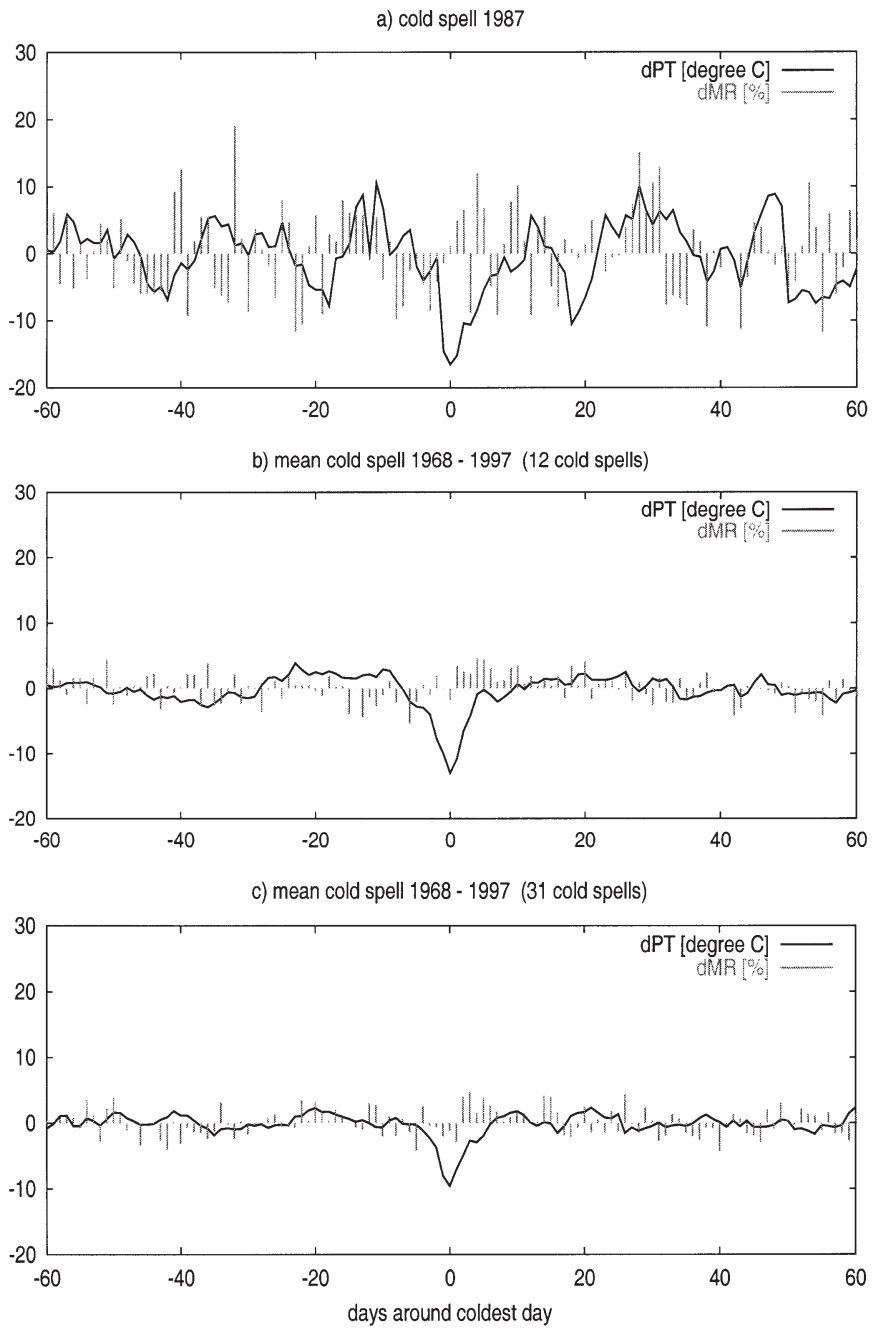

Fig. 13. Mean dPT and dMR from the smoothed time series of PT and MR for (a) the most severe cold spell, (b) the 12 most severe cold spells between 1968 and 1997 (except the 1987 cold spell), and (c) 31 cold spells (13 most severe cold spells excluded) between 1968 and 1997 
The mean characteristics of the 12 most severe cold spells (except the 1987 cold spell) show a PT drop of $13^{\circ} \mathrm{C}$ below the 'expected' value and a total period of $13 \mathrm{~d}$ with below-'normal' values of PT (Fig. 13b). With a lag of $1 \mathrm{~d}$ in relation to the coldest day a period of $16 \mathrm{~d}$ began with higher than normal MR (i.e. a mean value of $\mathrm{dMR}=+2.2 \%)$. The highest $\mathrm{dMR}$ value $(+4.6 \%)$ was observed $4 \mathrm{~d}$ after the coldest day.

An evaluation of an additional 31 cold spells (13 most severe cold spells excluded) leads to similar results (Fig. 13c). On average a total period of $13 \mathrm{~d}$ with lower than normal temperatures in terms of PT occurred. The coldest day is characterised by a dPT value of $-9.6^{\circ} \mathrm{C}$. With a time lag of $2 \mathrm{~d}$ in relation to the coldest day, $15 \mathrm{~d}$ with higher than normal MRs (i.e. a mean value of $\mathrm{dMR}=+2.1 \%$ ) were observed. The highest $\mathrm{dMR}$ value $(+4.7 \%)$ was observed $3 \mathrm{~d}$ after the coldest day.

The mean characteristics of 44 cold spells in SW Germany from 1968 to 1997 are: duration of below normal PT values: $13 \mathrm{~d}$; coldest day: $\mathrm{dPT}=-10.7^{\circ} \mathrm{C}$; duration of above-normal MR values: $15 \mathrm{~d}$ with mean increase in mortality, $\mathrm{dMR}=+2 \%$; and mean net $\mathrm{dMR}$ value over a period of 2 mo following the coldest day: $\mathrm{dMR}=$ $+0.25 \%$.

It is surprising that both thermal extremes in $30 \mathrm{yr}$ occurred in 1987. Indeed, the day with the absolutely lowest daily mean PT $\left(-24.7^{\circ} \mathrm{C}\right)$ occurred in 1987 , while the highest value of PT $\left(29.5^{\circ} \mathrm{C}\right)$ was reached in 1988 . The value of $29^{\circ} \mathrm{C}$ during the heat wave in 1987 was slightly lower, but presented a strong warming after a rather cool period. The relative definition of extremes led to this coincidence in 1987, because the hottest days of $1988\left(29.5^{\circ} \mathrm{C}\right), 1994\left(29.1^{\circ} \mathrm{C}\right)$ and $1995\left(29.3^{\circ} \mathrm{C}\right)$ occurred later in the year and were preceded by a period with relatively high $\mathrm{PT}$.

\section{DISCUSSION}

The results of this investigation indicate that the health of the population of SW Germany is sensitive to climate in terms of the thermal environmental conditions.

The study confirms the seasonal pattern of total mortality that has been described earlier in the literature mainly for mortality due to cardiovascular diseases (Sakamoto-Momiyama 1977). The time lag of $21 \mathrm{~d}$ that has been found between the maximum PT and the minimum MR could indicate a certain acclimatisation of the population to the prevailing thermal conditions, which requires on average a $3 \mathrm{wk}$ adjustment period. Excepting the seasonal variation the mean values of 30 yr of mortality rates were expected to show non-systematic day-to-day fluctuations. However, variations lasting from some days to weeks occurred especially in summer and winter, the reason for which is still unclear. The closer autocorrelation of PT in comparison to MR meets expectations.

The relation of total MR to the complex conditions of atmospheric heat exchange of the human being in terms of the parameter PT has been found to correspond to the generalised relation between cardiovascular mortality and air temperature (Frost \& Auliciems 1993), except the decreases in MR at the extreme ends of the temperature distribution. There are rarely extreme thermal conditions in the temperate climate of SW Germany. This causes the possibility of an incorrect interpretation at the extreme ends due to the use of PT classes: a minimum number of cases per class is required, and hence the classes at the fringes also contain all cases beyond their borders. However, a plot of the raw mortality data against PT values (not classes) disproves this possibility (not shown).

MR are lowest during comfort conditions, when the demands on the thermal regulatory system of the human body are minimal. Obviously the population of SW Germany is best adapted to thermal conditions in terms of a daily mean PT of $14^{\circ} \mathrm{C}$ (PT class $12-16^{\circ} \mathrm{C}$ ). Also, adaptation by means of the insulation properties of clothing can easily be achieved under the conditions of the neighbouring classes. PT is not directly comparable to temperature $(\mathrm{T})$ due to the consideration of the impact of (mainly) wind velocity and radiation on the human heat exchange. On average (1968-1997) the comfort range in terms of $\mathrm{T}$ deviates about $+2^{\circ} \mathrm{C}$ from $\mathrm{PT}$, but this statement has to be considered with caution because it obviously depends on the actual weather conditions. (In Germany the difference between $\mathrm{PT}$ and $\mathrm{T}$ can reach $15^{\circ} \mathrm{C}$ under summer conditions.)

Death rates increase with increasing cold stress, i.e. with increasing demands on thermal regulation. It must be assumed that, in winter, people are usually not, or at least only for a short time, exposed to the outdoor conditions described by PT. Therefore the seasonal pattern in winter is assumed to be mainly caused by a higher probability of infections rather than by the direct exposure to cold stress (Eurowinter Group 1997). Statements on reduced winter mortality in a warmer world (Langford \& Bentham 1995, Keatinge et al. 2000) due to climate change (Kovats et al. 1999) have to be considered as highly speculative until the mechanisms for the adverse effects are satisfactorily understood.

In the process that finally leads to death, extreme events are far more significant than other impacts. However, conclusions concerning deaths attributable to extreme events have to be considered with caution, because they are sensitive to the baseline estimates (expected values of mortality). Here the baseline is determined by the smoothing procedure (Gaussian 
filter); other baseline estimates, such as other filters or percentile-approaches, might result in other interpretations.

Events of low PT values in relation to the seasonally expected values (cold spells) show an increase in MR which is delayed by 1 to $2 \mathrm{~d}$ in relation to the coldest day. There are similar results from other climates showing a shorter-term temperature effect (overlying the seasonal trend in the temperature-death relationship) which appears to be manifest in increased mortality some days following unusually cold days (Auliciems et al. 1997). The mean increase of $2 \%$ above the seasonally expected values of MR is not very marked, but lasts for about $2 \mathrm{wk}$. During a time period of 2 mo following the cold stress events, net excess mortality occurs that exceeds possible effects of short-term mortality displacement. Direct cause-effect relationships between PT and indoor thermal regulation with people living in temperature-controlled buildings are still unclear. Probably cold spells result in a persistent disturbance of healthy indoor conditions by initiating infections during short outdoor exposure. Pathogens, encountering reduced resistance of the population in winter, can spread more easily, because people live closer together in rooms with reduced ventilation. Additionally, socioeconomic effects (such as heating behaviour) might be important (Eurowinter Group 1997).

During the seasonal minimum of $\mathrm{MR}$ in summer, death rates sharply increase with increasing heat load, reaching their highest values - of about $12 \%$ above the seasonally expected MR - during heat episodes even in the temperate climate of SW Germany. Using a plot of MR against PT thresholds during heat waves (not shown), results from other climates, showing that significantly more than expected deaths occur after exceeding a certain threshold for thermal stress (Kalkstein \& Smoyer 1993, Katsouyanni et al. 1993), could not be confirmed. Increasing heat load means more demands on the cardiovascular system to enable better thermal regulation. Though strong demands on thermal regulation are common to both cold spells and heat waves, their mean characteristics differ probably due to the different physiological mechanisms involved. As opposed to cold spells, events of high PT values in relation to the seasonally expected values (heat waves) show an increase in MR with no delay. The mean increase in MR (+3.9\%) during heat waves is about twice as high as during cold spells. The increase in MR above expected values lasts for a shorter period and is followed by a mean period of $19 \mathrm{~d}$ of below-normal values of MR. This possibly indicates effects of short-term mortality displacement, i.e. people die who would have died in the short term anyway. Problems related to such conclusions have been men- tioned in the literature before (Whitman et al. 1997). Obviously there is no uniform behaviour in the time series concerning the residue of mortality attributable to a heat wave (integral of dMR over the time period of 2 mo following the heat episode; a positive value is also referred to as 'net' excess mortality). It seems to depend on the intensity of the heat wave as to whether or not net excess mortality occurs. The 16 most severe heat waves result in a small value $(0.2 \%)$ of mean net excess mortality, i.e. a total number of 30 additional deaths occurred in association with heat waves in SW Germany. The analysis of 35 additional heat episodes did not show net excess mortality. Hence, generalised conclusions and the question of a possible threshold remain uncertain.

The timing of the occurrence of heat load episodes within the season is usually assumed to be important as well: heat load conditions earlier in the season are expected to have greater effects on mortality (Kalkstein \& Smoyer 1993, Kalkstein \& Greene 1997). Though no systematic investigation of this question has been done in this research, the relations of dMR and dPT from the monthly mean value in July and August support this assumption (not shown). Greatest values of dMR were found in the warmest PT class in July, while dMR in the same PT class in August is lower, possibly indicating greater effects of earlier heat load episodes. Susceptible persons died, while the others adapted to thermal stress.

The thermal environment obviously influences humans in terms of both prevailing conditions and changes. During persistent cold stress as well as heat load the extreme thermal conditions influence $M R$, while during moderate thermal conditions the temporal changes in PT on a time scale of $1 \mathrm{wk}$ become more significant. Possible influences of other time scales of thermal changes have not yet been investigated. In all seasons atmospheric changes on a scale of $1 \mathrm{wk}$ towards warmer conditions in terms of PT result in adverse health effects (increased MRs), while changes towards colder conditions provide relief. This is surprising for the winter; however it turned out to be especially important for moderate thermal conditions (e.g. mild periods in winter). As long as the cold stress intensities are not too strong, cooling leads to reduced strain. Obviously PT7 can serve as an indicator of adaptation. The question of a threshold is still open.

In the transitional season from winter to summer, larger day-to-day variations in PT occur, which require stronger adaptation activities of the thermal regulatory system, resulting in a higher MR compared to the conditions in autumn with comparable PT values. The explanation of about $25 \%$ variance in total mortality by the environmental factor PT in summer is extraordinarily significant. This can be assumed to be an indica- 
tion of the close indoor-outdoor relationship in PT and/or the more frequent exposure to outdoor conditions in summer. Hence PT seems to be more representative of the thermal environment in summer to which the human being is exposed. In winter the correlation coefficients between dMR and dPT (deviations from the smoothed values) show only non-significant values, but marked time lags of $8 \mathrm{~d}$ and more, possibly indicating that other physiological mechanisms are involved. The results concerning the correlation coefficients are not independent from the lags used and the smoothing procedure. However, the correlation coefficients for the absolute values of MR and PT show similar results to dMR and dPT.

Although morbidity data are not yet available, it is likely that people with an insufficient adaptation capacity, due to age or disease, are at most risk to thermal stress, because even a slight disturbance can cause a change in their physical condition for the worse. It seems highly possible that, apart from mortality and morbidity, the thermal environment also impacts well-being and efficiency of healthy people. This should be an area for further investigation; the problems are particularly relevant for public health.

Additionally, the prospect of a change in climate (though not yet certain, especially in its regional consequences) includes the possibility of a higher frequency and/or intensity of heat waves in the future (Kovats et al. 1999, McGeehin \& Mirabelli 2001). The moderate climate of SW Germany is characterised by only rare extremes; however regions with only irregularly recurring extremes are expected to be especially affected (Kalkstein 1993). International studies, e.g. the WMO/WHO/UNEP showcase projects, show that interventions by local health agencies and doctors can reduce mortality during extreme weather in summer (Kalkstein 2000). Based on this research and further investigations, heat-health-watch-warning-systems (Sheridan \& Kalkstein 1999, Kalkstein 2001) should be developed for application in Germany to reduce the vulnerability of the population to thermal extremes by locally specific intervention measures.

Acknowledgements. The authors thank Heiner-Michael Walther for undertaking parts of the analysis in his MS thesis at the Institut für Meteorologie und Klimaforschung, Universität Karlsruhe, Germany.

\section{LITERATURE CITED}

Alberdi J (1998) Daily mortality in Madrid community 19861992: relationship with meteorological variables. Eur J Epidemiol 14:571-578

Anderson HR, Ponce de Leon A, Bland JM (1996) Air pollution and daily mortality in London: 1987-92. Br Med J 312: 665-669

Auliciems A, Frost D, Siskind V (1997) The time factor in mor- tality: weather associations in a subtropical environment. Int J Biometeorol 40:183-191

Ballester F (1997) Mortality as a function of temperature: a study in Valencia, Spain, 1991-1993. Int J of Epidemiol 26: 551-561

Blazejczyk K (1994) New climatological-and-physiological model of the human heat balance outdoors (MENEX) and its applications in bioclimatological studies in different scales. Zeszyty IgiPZ PAN 28:27-58

Davis RE, Knappenberger PC, Michaels PJ, et al. (1999) Trends in weather-adjusted human mortality in U.S. cities. In: de Dear R, Potter JC (eds) Proc 15th Int Congr Biometeorol and Int Conf Urban Climatol, Sydney, Australia, 812 November 1999, CD. MacQuarie University, Sydney

De Dear R, Pickup J (2000) An outdoor thermal environment index (OUT_SET ${ }^{*}$ ). Part II. Applications. In: De Dear R, Kalma J, Oke T, Auliciems A (eds) Biometeorology and urban climatology at the turn of the millennium. Selected Papers from the Conference ICB-ICUC'99 (Sydney, 8-12 November 1999). WMO, Geneva, WCASP-50, p 258-290

Eng H, Mercer J (1998) Seasonal variations in mortality caused by cardiovascular diseases in Norway and Ireland. J Cardiovascular Risk 5:89-95

Eurowinter Group (1997) Cold exposure and winter ischaemic heart diseases, cerebrovascular diseases, and all causes in warm and cold regions of Europe. Keeting WR, Donaldson GC (coords). The Lancet 349:1341-1346

Fanger PO (1972) Thermal comfort. Analysis and applications in environmental engineering. McGraw-Hill, New York

Frost DB, Auliciems A (1993) Myocardial infarct death, the population at risk and temperature habituation. Int J Biometeorol 37:46-51

Gagge AP, Fobelets AP, Berglund PE (1986) A standard predictive index of human response to the thermal environment. ASHRAE Trans 92:709-731

Guest CS, Willson K, Woodward AJ and 4 others (1999) Climate and mortality in Australia: retrospective study, 197990, and the predicted impacts in five major cities in 2030. Clim Res 13:1-15

Höppe P (1993) Heat balance modelling: multi-author review. Experientia 49(11):741-746

Höppe P (1999) The physiological equivalent temperature-a universal index for the biometeorological assessment of the thermal environment. Int J Biometeorol 43:71-75

Horikoshi T, Tsuchikawa T, Kurazumi Y, Matsubara N (1995) Mathematical expression of combined and separate effect of air temperature, humidity, air velocity and thermal radiation on thermal comfort. Arch Complex Environ Stud $7(3-4): 9-12$

Horikoshi T, Einishi M, Tsuchikawa T, Imai H (1997) Geographical distribution and annual fluctuation of thermal environmental indices in Japan: development of a new thermal environmental index for outdoors and its application. J Human-Environ Syst 1(1): 87-92

Jendritzky G, Kalkstein L (1997) Climate services to the health sector. WMO Bull 46(1):30-32

Jendritzky G, Nübler W (1981) A model analysing the urban thermal environment in physiologically significant terms. Arch Meteorol Geophys Bioclimatol Ser B 29:313-326

Jendritzky G, Menz G, Schmidt-Kessen W, Schirmer H (1990) Methodik zur raumbezogenen Bewertung der thermischen Komponente im Bioklima des Menschen (Fortgeschriebenes Klima-Michel-Modell). ARL-Verlag, Akademie für Raumforschung und Landesplanung, Beiträge 114, Hanover

Jendritzky G, Bucher K, Laschewski G, Walther H (2000a) Atmospheric heat exchange of the human being, biocli- 
mate assessments, mortality and thermal stress. Int J Circumpolar Health 59:222-227

Jendritzky G, Staiger H, Bucher K, Graetz A, Laschewski G (2000b) The perceived temperature - the method of the Deutscher Wetterdienst for the assessment of cold stress and heat load for the human body. In: Internet Workshop on Windchill, hosted by Environment Canada, April 3-7, 2000; available at http://windchill-conference.ec.gc.ca/ workshop/papers/pdf/session_1_paper_4_e.pdf

Kalkstein LS (1993) Health and climate change: direct impacts in cities. The Lancet 342:1397-1399

Kalkstein LS (2000) Biometeorology-looking at the links between weather, climate and health. WMO Bull 50:1-6

Kalkstein LS (2001) Saving lives during extreme weather in summer. Br Med J 321:650-651

Kalkstein LS, Greene JS (1997) An evaluation of climate/mortality relationships in large U.S. cities and the possible impacts of a climate change. Environ Health Perspect 105: 84-93

Kalkstein LS, Smoyer KE (1993) The impact of climate change on human health: some international implications. Experientia 49 (11):969-979

Katsouyanni K, Pantazopoulou A, Touloumi G, Tselepidaki I and 4 others (1993) Evidence for interaction between air pollution and high temperature in the causation of extreme mortality. Arch Environ Health 48:235-242

Katsouyanni K, Touloumi G, Spix C, Schwartz J and 9 others (1997) Short-term effects of ambient sulphur dioxide and particulate matter on mortality in 12 European cities: results from time series data from the APHEA project. $\mathrm{Br}$ Med J 314:1658-1663

Keatinge WR, Donaldson GC, Cordioli E, Martinelli M and 4 others (2000) Heat related mortality in warm and cold regions of Europe: observational study. Br Med J 321: 670-673

Kovats RS, Hains A, Stanwell-Smith R and 3 others (1999) Climate change and human health in Europe. Br Med J 318: $1682-1685$

Kunst AE, Looman CWN, Mackenbach JP (1993) Outdoor air temperature and mortality in the Netherlands: a timeseries analysis. Am J Epidemiol 137(3):331-341

Laake K, Sverre J (1996) Winter excess mortality: a comparison between Norway and England plus Wales. Age and Ageing 25:343-348

Langford ICH, Bentham G (1995) The potential effects of climate change on winter mortality in England and Wales. Int J Biometeorol 38:141-147

Larsen U (1990) Short-term fluctuations in death by cause, temperature and income in the United States, 1938-1985. Social Biol 37:173-187

Lerchl A (1998) Changes in the seasonality of mortality in Germany from 1946-1995: the role of temperature. Int

Editorial responsibility: Robert Davis,

Charlottesville, Virginia, USA
J Biometeorol 42:84-88

McGeehin MA, Mirabelli M (2001) The potential impacts of climate variability and change on temperature-related morbidity and mortality in the United States. Environ Health Perspect 109(Suppl 2):185-189

Pan W, Li L, Tsai M (1995) Temperature extremes and mortality from coronary heart disease and cerebral infarctions in elderly Chinese. The Lancet 345:353-355

Pell J, Cobbe S (1999) Seasonal variations in coronary heart disease. Q J Med 12:689-696

Pickup J, de Dear R (2000) An outdoor thermal comfort index (OUT_SET**). Part I. The model and its assumptions. In: De Dear R, Kalma J, Oke T, Auliciems A (eds) Biometeorology and urban climatology at the turn of the millennium. Selected Papers from the Conference ICB-ICUC'99 (Sydney, 8-12 November 1999). WMO, Geneva, WCASP-50, p 279-283

Rooney C, McMichael AJ, Kovats RS, Coleman MP (1998) Excess mortality in England and Wales and Greater London during the 1995 heatwave. Epidemiol Community Health 52:482-486

Saez M, Sunyer J, Tobias A and 2 others (2000) Ischaemic heart disease mortality and weather temperature in Barcelona, Spain. Eur J Public Health 10(1):58-63

Sakamoto-Momiyama M (1977) Seasonality in human mortality. University of Tokyo Press, Tokyo

Sheridan SC, Kalkstein LS (1999) Heat watch-warning systems in urban areas. World Resour Rev 10:375-383

Smoyer KE, Rainham DGC, Hewko JN (2000) Heat-stressrelated mortality in five cities in Southern Ontario: 1980-1996. Int J Biometeorol 44:190-197

Staiger H, Bucher K, Jendritzky G (1997) Gefühlte Temperatur: Die physiologisch gerechte Bewertung von Wärmebelastung und Kältestress beim Aufenthalt im Freien mit der Maßzahl Grad Celsius. Ann Meteorol 33:100-107

Steadman RG (1984) A universal scale of apparent temperature. J Clim Appl Meteorol 23:1674-1687

Steadman RG (1994) Norms of apparent temperature in Australia. Aust Meteorol Mag 43:1-16

VDI (1998) Guideline VDI. 3787, Part 2. Environmental meteorology: methods for the human-biometeorological evaluation of climate and air quality for urban and regional planning. Part I. Climate. Beuth, Berlin

Whitman S, Good G, Donoghue ER and 3 others (1997) Mortality in Chicago attributed to the July 1995 heatwave. Am J Public Health 87:1515-1518

Zeger SL, Dominici F, Samet J (1999) Harvesting-resistant estimates of air pollution effects on mortality. Epidemiology 10:171-175

Zmirou D, Schwartz J, Saez M, Zanobetti A and 9 others (1998) Time-series analysis of air pollution and cause-specific mortality. Epidemiology 9(5):495-503

Submitted: February 23, 2001; Accepted: September 18, 2001 Proofs received from author(s): March 5, 2002 